\title{
A report on chromosomal translocation types in relation to male infertility
}

\author{
Nidhi P Shah ${ }^{1}$, Krishna Mistry ${ }^{2}$, Mudra Kansara ${ }^{3}$ K Sonali ${ }^{4}$, Nirali Thakkar ${ }^{5}$, Parth S Shah ${ }^{6}$, \\ Sandip C Shah ${ }^{7}$, Mandava V Rao ${ }^{8 *}$ \\ From ${ }^{1}$ Chief, Cytogenetic Division, ${ }^{2}$ Sr. Lab Technician, ${ }^{3}$ Cytogeneticist, ${ }^{4}$ Jr. Lab Technician, ${ }^{5}$ Bioinformatician, ${ }^{6}$ Head, Genomic Medicine, ${ }^{7}$ Lab \\ Director, Department of Genomic Medicine, Cytogenetic Division, Neuberg-Supratech Referral Laboratory Kedar Building, ${ }^{8}$ Research Director and \\ Ex-Director, Department of Zoology, BMTC and Human Genetics, School of Sciences, Gujarat University, Ahmedabad, Gujarat, India
}

Correspondence to: Dr. Mandava V Rao, School of Sciences, Gujarat University, Ahmedabad, Gujarat, India. E-mail: manvrao@gmail.com Received - 03 November 2021

Initial Review - 15 December 2021

Accepted - 20 December 2021

\section{ABSTRACT}

Introduction: Male infertility (MI) in about $50 \%$ of couples is constituted due to genetic, hormonal, and epigenetic factors. Almost $10 \%$ of it is contributed to genetic anomalies. Objectives: This study was undertaken in 787 males with infertility and the impacts of the type of translocations in these cases were studied in relation to MI. Materials and Methods: Five milliliters (ml) of blood were drawn from referred cases suspected with MI and were used for cytogenetic analysis with Giemsa stain following International System for Human Cytogenetic Nomenclature. Results: Of 6142 referral cases, 787 were detected with MI (787/6142; $12.8 \%)$. Forty-four translocations (44/787; 5.6\%) were detected in 787 infertile men. Other chromosomal abnormalities were $21 \%$ $(167 / 787)$ in them. Among all translocations, an autosome-autosomal translocations were higher in frequency $(24 / 787 ; 3.1 \%)$ than Robertsonian $(15 / 787 ; 1.9 \%)$ and autogonosomal translocations $(5 / 787 ; 0.6 \%)$. Few translocations seemed to be rare as our knowledge is concerned. Maharashtra had high frequency of translocations followed by Delhi union territory (UT) and Gujarat (07 each) and other states. Most of the translocations were related to infertility. Seven males had primary infertility (7/44) and six with secondary type (6/44) in this study. Conclusions: These reciprocal translocations are important in causation of infertility affecting testicular spermatogenesis. Few are rare in our study. Such cases are clinically suggested for counseling before adopting assisted reproductive technologies.

Key words: Reciprocal translocations, Types, Karyotype, Male infertility, Patients

$\mathrm{I}$ nfertility is one of the health-related concerns. In the male, it is caused by factors such as hormonal, physiological, psychological, neuronal, environmental, and genetic factors. Male infertility (MI) contributes about $50 \%$ of couples [1]. Genetic causes include chromosomal and Y chromosome microdeletion including gene mutations [2]. Keymolen et al. [3] Xie et al. [4], and Ching et al. [5] documented that chromosomal translocations play a major role in causation of MI. Cytogenetic analysis of patients is a basis for the evaluation of these genetic diseases [6-8]. Vozdova et al. [9] mentioned that Robertsonian (Rob) and other reciprocal translocations are associated with infertility and low sperm counts. Yq microdeletions are also second factor for infertility in the male. Deletions in azoospermia factor cause abnormal semen types such as azoospermia, oligozoospermia, and others [1,10-13], leading to fertility anomalies. It has been reported that the chromosomal translocations which are structural anomalies reduce fertility in both men and women. These are higher (6-10\%) among infertile men compared to the general population $[14,15]$. Hence, this study was undertaken from March 2019 to March 2021 (2 years) to evaluate chromosomal translocations in referral cases with infertility on advice of clinicians for in our Neuberg Supratech Referral Laboratories (NSRLs), Ahmedabad, Gujarat, India.

\section{MATERIALS AND METHODS}

\section{Patient Selection}

Patients suspected infertility as suggested by clinician ranging in age from 21 to 43 years was referred to our NSRLs, Ahmedabad, for blood collection with duly filled consent forms. Blood samples from other centers were carefully transported at $4^{\circ} \mathrm{C}$ and were also pooled in our main centers, Ahmedabad, during this period of 2 years (March 2019-March 2021) for analysis.

\section{Karyotyping from Blood}

The blood samples were collected in sodium heparin vials as per the instructions and then utilized for karyotyping analysis. A volume of 0.5 milliliter $(\mathrm{ml})$ of blood sample was used for chromosome preparation with phytohemagglutinin as mitogen using the method of Moorhead et al. [16]. These samples are incubated at $37^{\circ} \mathrm{C}$ (post-colchicine addition, $30 \mu \mathrm{l}$ at $69^{\text {th }} \mathrm{h}$ ) for $72 \mathrm{~h}$. Then, they were harvested after treating with hypotonic potassium chloride solution. The metaphase slides were prepared with fixative and stained with $G$ bands after trypsin and Giemsa or G-banding. These slides were subjected to Carl Zeiss Automated 
Meta-systems for karyotyping. Twenty metaphase plates were prepared for each sample to identify chromosomal anomalies using International System for Cytogenetic Nomenclature [17].

\section{Statistics}

Descriptive statistics were prepared using Excel sheet data of patients. The categorical variables were mentioned as counts and frequencies.

\section{RESULTS}

Karyotyping was done in 6142 referral cases. Only 787 cases were detected with infertility in males $(787 / 6142 ; 12.8 \%)$. Among 787 patients; 167 were with chromosomal abnormalities $(167 / 787 ; 21 \%)$ and 44 had chromosomal translocations (44/787; $5.6 \%$ ) in these males. From 44 translocations, Rob translocations constituted $1.9 \%(15 / 787)$ and auto-autosomal translocations were $3.1 \%$ (24/787) followed by gono-autosomal reciprocal translocations $(5 / 787 ; 0.6 \%)$ (Tables $1-3)$. Reciprocal autosomal translocations contributed high frequency followed by Rob translocations and gonosomal types. Few were seemed to be rare (Tables 1-3). Among 44 translocations in our study, 20 cases were from Maharashtra, whereas Gujarat and Delhi (UT) contributed each of seven cases (7/44) followed by other states (Fig. 1). Most of the males were infertile (31/44) and few were with primary (7) and secondary (6) types of infertility (Tables 1-3). Examples of each translocation type were presented (Figs. 2-4).

\section{DISCUSSION}

Chromosomal translocations are the most structural chromosomal anomalies. These are known to reduce fertility in men and women. A study conducted by Dong et al. [1] who showed that $16.1 \%$ had chromosomal abnormalities in infertile men with
$2.1 \%$ translocations. Other study also stated that infertile males have high frequency of the reorganization of chromosome architecture including Rob translocations compared to general population [18]. In our study of 6142 referral cases, the infertile male cases contributed to $12.8 \%$ (787/6142). Among 787 infertile men, 167 had chromosomal anomalies (21\%), whereas 44 had total reciprocal translocations (5.6\%) aging from 21 to 43 years. Fifteen cases suffered with Rob type $(15 / 787 ; 1.9 \%)$ and 24 infertile men exhibited an autosome-autosomal translocations $(24 / 787,3.1 \%)$ and others had gonosome-autosomal reciprocal types $(05 / 787 ; 0.6 \%)$. The frequencies of these types are well comparable with the study of Dong et al. [1] and are related to MI. Further, they documented that these translocations reduce spermatogenesis and are correlated to reduced sperm quality. No changes were noticed in hormone level except testosterone levels where markedly affected in Rob and gonosome-autosomal reciprocal cases. These translocation groups might have not overcome meiosis I and become blocked differentiation of primary spermatocyte stage forcing them to oligozoospermia. Infertile men with 44 translocations, higher frequency of autosome-autosomal translocations were seen in this study, as reported by earlier workers $[1,4,5]$. Parent carriers with reciprocal translocations are at a risk of infertility and recurrent pregnancy loss (RPL). The incidence of balanced autosomal translocations in infertile men has been reported between 1.6 and $6.65 \%$ to support our data $[5-7,19,20]$. Two rare cases of double autosomeautosome translocations $\mathrm{t}(5 ; 21) / \mathrm{t}(11 ; 21)$ and $\mathrm{t}(1 ; 8) / \mathrm{t}(7 ; 15)$ and another case of translocation $\mathrm{t}(19 ; 20)$ with heteromorphism $\left(21 \mathrm{ps}^{+} ; 22 \mathrm{ps}^{+}\right)$were noticed. Similarly, cases with reciprocal translocations between Y chromosome and an autosome are rare and highly associated with male sterility [21]. Such patients of five were obtained in our study.

Rob translocations are also common balanced type, occur between acrocentric chromosomes of 13, 14, 15, 21, and 22 . Their incidence in general population is $0.1 \%$ with $1.1 \%$ in

Table 1: Robertsonian translocations in our study

\begin{tabular}{|c|c|c|c|c|}
\hline Case no. & Age (Year) & State & Karyotype & History \\
\hline 1 & 26 & Gujarat & $\begin{array}{l}45, X Y, \operatorname{inv}(9),(p 11 ; q 13), \operatorname{rob}(13 ; 14) \\
(q 10 ; q 10), 21 p s^{+*}\end{array}$ & Infertility \\
\hline 2 & 43 & Rajasthan & $45, \mathrm{XY}, \operatorname{rob}(13 ; 14)(\mathrm{q} 10 ; \mathrm{q} 10)$ & Infertility \\
\hline 3 & 33 & Tamil Nadu & $45, X Y, \operatorname{rob}(13 ; 14)(q 10 ; q 10)$ & Infertility \\
\hline 4 & 42 & Maharashtra & $45, X Y, \operatorname{rob}(13 ; 14)(q 10 ; q 10)$ & Infertility \\
\hline 5 & 39 & Tamil Nadu & $45, X Y, \operatorname{rob}(13 ; 14)(q 10 ; q 10)$ & Infertility \\
\hline 6 & 39 & Maharashtra & $45, X Y, \operatorname{rob}(13 ; 14)(q 10 ; q 10)$ & Infertility \\
\hline 7 & 39 & Maharashtra & $45, X Y, \operatorname{rob}(13 ; 14)(\mathrm{q} 10 ; \mathrm{q} 10)$ & Secondary infertility \\
\hline 8 & 38 & Delhi (UT) & $45, X Y, \operatorname{rob}(13 ; 14)(q 10 ; q 10)$ & Infertility \\
\hline 9 & 38 & Maharashtra & $45, X Y, \operatorname{rob}(13 ; 14)(q 10 ; q 10)$ & Primary infertility \\
\hline 10 & 33 & Maharashtra & $45, X Y, \operatorname{rob}(13 ; 15)(\mathrm{q} 10 ; \mathrm{q} 10)$ & Infertility \\
\hline 11 & 28 & Tamil Nadu & $45, X Y, \operatorname{rob}(13 ; 22)(q 10 ; q 10)$ & Infertility \\
\hline 12 & 43 & West Bengal & $45, X Y, \operatorname{rob}(14 ; 21)(q 10 ; q 10)$ & Infertility \\
\hline 13 & 32 & Maharashtra & $45, X Y, \operatorname{rob}(15 ; 21)(q 10 ; q 10)$ & Primary infertility \\
\hline 14 & 26 & UT & $45, X Y, \operatorname{rob}(22 ; 22)(q 10 ; q 10)$ & Infertility \\
\hline 15 & 33 & Maharashtra & $45, X Y, \operatorname{rob}(3 ; 14)(q 10 ; q 10)$ & Primary infertility \\
\hline
\end{tabular}

*Rob with inversion $q$ and $21 \mathrm{ps}+($ Rare); UT=Union territory 
Table 2: Autosome-autosomal translocations in our study

\begin{tabular}{|c|c|c|c|c|}
\hline Case no. & Age (Year) & State & Karyotype & History \\
\hline 1 & 31 & Tamil Nadu & $\begin{array}{l}45, X Y, t(5 ; 21)(\mathrm{p} 15 ; \mathrm{q} 10)[15] / 45, \mathrm{XY}, \mathrm{t}(11 ; 21) \\
(\mathrm{q} 25 ; \mathrm{q} 10)[5]^{* *}\end{array}$ & Infertility \\
\hline 2 & 31 & Maharashtra & $46, \mathrm{XY}, \mathrm{t}(5 ; 17)(\mathrm{q} 10 ; \mathrm{p} 10)$ & Secondary infertility \\
\hline 3 & 31 & Maharashtra & $46, X Y, t(1 ; 12)(q 31 ; q 14)$ & Primary infertility \\
\hline 4 & 33 & Maharashtra & 46, XY, t (1;17)(q10;p10) & Secondary infertility \\
\hline 5 & 21 & Gujarat & $46, \mathrm{XY}, \mathrm{t}(1 ; 2)(\mathrm{p} 36.2 ; \mathrm{p} 13)$ & Infertility \\
\hline 6 & 38 & Maharashtra & $46, \mathrm{XY}, \mathrm{t}(1 ; 3)(\mathrm{p} 22 ; \mathrm{q} 21)$ & Infertility \\
\hline 7 & 37 & Maharashtra & $46, X Y, t(1 ; 3)(q 10 ; p 10)$ & Primary infertility \\
\hline 8 & 30 & Madhya Pradesh & $46, \mathrm{XY}, \mathrm{t}(1 ; 6)(\mathrm{p} 32 ; \mathrm{q} 27)$ & Infertility \\
\hline 9 & 43 & Delhi (UT) & $46, \mathrm{XY}, \mathrm{t}(1 ; 8)(\mathrm{q} 31 ; \mathrm{q} 11.2) / 46, \mathrm{XY}, \mathrm{t}(7 ; 15)(\mathrm{q} 32 ; \mathrm{q} 26)^{* *}$ & Infertility \\
\hline 10 & 26 & Gujarat & 46, XY, t $(13 ; 19)(22 \mathrm{q} ; 12 \mathrm{p})$ & Infertility \\
\hline 11 & 29 & Gujarat & $46, \mathrm{XY}, \mathrm{t}(17 ; 19)(\mathrm{p} 12 ; \mathrm{p} 13)$ & Infertility \\
\hline 12 & 39 & Maharashtra & $46, \mathrm{XY}, \mathrm{t}(19 ; 20)(\mathrm{q} 13.1 ; \mathrm{q} 13.3), 21 \mathrm{ps}+, 22 \mathrm{ps}+* * *$ & Primary infertility \\
\hline 13 & 48 & Gujarat & $46, \mathrm{XY}, \mathrm{t}(2 ; 17)(\mathrm{p} 16 ; \mathrm{p} 11.2)$ & Infertility \\
\hline 14 & 29 & West Bengal & 46, XY, t (2;7)(q32;p21) & Infertility \\
\hline 15 & 28 & West Bengal & $46, X Y, t(4 ; 6)(q 35 ; q 24)$ & Infertility \\
\hline 16 & 35 & Maharashtra & $46, X Y, t(5 ; 6)(p 15 ; q 21)$ & Secondary infertility \\
\hline 17 & 32 & Maharashtra & 46, XY, t (6;10)(p23;q22) & Secondary infertility \\
\hline 18 & 37 & UT & $46, \mathrm{XY}, \mathrm{t}(6 ; 16)(\mathrm{p} 21 ; \mathrm{p} 13.1)$ & Infertility \\
\hline 19 & 40 & West Bengal & 46, XY, t (6;9) (q22;p21) & Infertility \\
\hline 20 & 41 & Maharashtra & $46, X Y, t(7 ; 8)(q 21 ; q 24)$ & Secondary infertility \\
\hline 21 & 24 & UT & 46, XY, t (8;10)(p23;q22) & Infertility \\
\hline 22 & 33 & Maharashtra & $46, \mathrm{XY}, \mathrm{t}(8 ; 10)(\mathrm{q} 24.2 ; \mathrm{p} 11.2)$ & Infertility \\
\hline 23 & 38 & Gujarat & $46, \mathrm{XY}, \mathrm{t}(9 ; 12)(\mathrm{p} 24 ; \mathrm{q} 24.1)$ & Infertility \\
\hline 24 & 41 & Gujarat & $46, \mathrm{XY}, \mathrm{t}(9 ; 22)(\mathrm{q} 13 ; \mathrm{q} 11.2)$ & Infertility \\
\hline
\end{tabular}

**Double translocations, ***translocation with polymorphism; UT=Union territory

Table 3: Gonosome-autosomal translocations in our study

\begin{tabular}{|c|c|c|c|c|}
\hline Case no. & Age (Year) & State & Karyotype & History \\
\hline 1 & 36 & Delhi (UT) & $\begin{array}{l}\text { 46, X, t (Y; } \\
13),(\mathrm{q} 11.21 ; \mathrm{q} 22)\end{array}$ & Infertility \\
\hline 2 & 28 & Maharashtra & $46, \mathrm{X}, \mathrm{t}(\mathrm{Y} ; 13),(\mathrm{q} 12 ; \mathrm{q} 32)$ & Infertility \\
\hline 3 & 25 & Assam & $\begin{array}{l}46, \mathrm{X}, \mathrm{t}(\mathrm{Y} ; \\
22),(\mathrm{p} 11.3 ; \mathrm{q} 11.2)\end{array}$ & Infertility \\
\hline 4 & 28 & Maharashtra & $46, \mathrm{X}, \mathrm{t}(\mathrm{Y} ; 3),(\mathrm{p} 11.2 ; \mathrm{q} 21)$ & Primary infertility \\
\hline 5 & 30 & Delhi (UT) & 46, X, t (Y; 3),(q12;p22) & Infertility \\
\hline
\end{tabular}

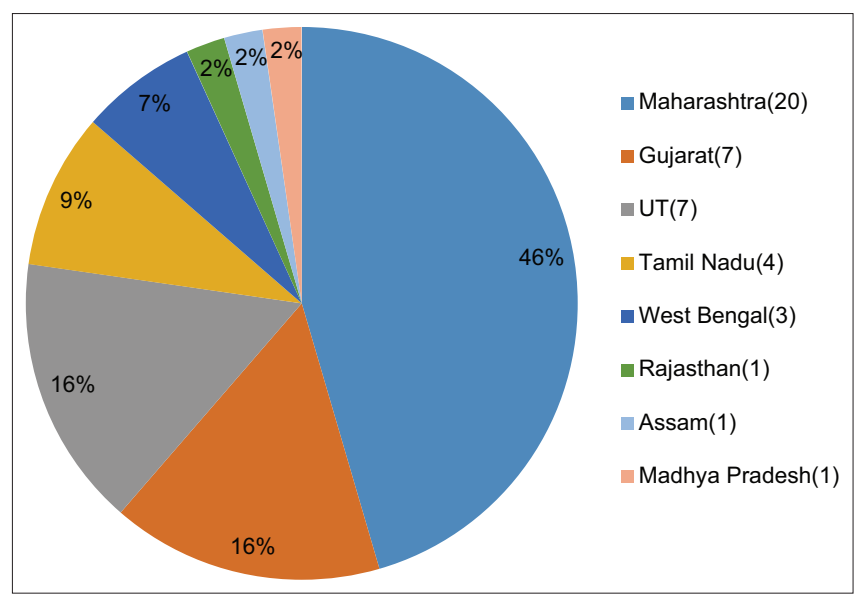

Figure 1: State-wise distribution percent of translocation in our study number in parentheses indicate cases. UT: Union territory

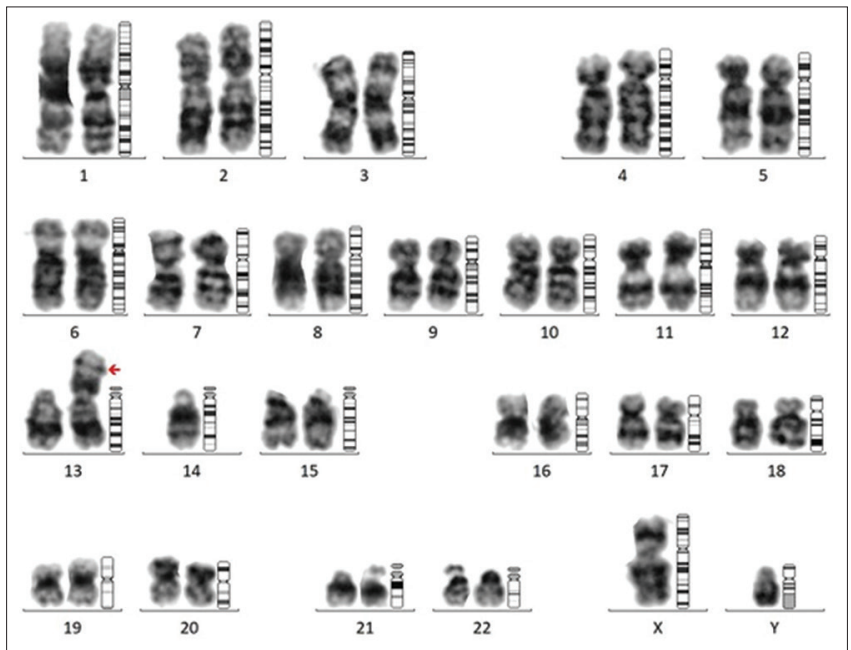

Figure 2: Typical Robertsonian translocation, $t(13 ; 14)$ 


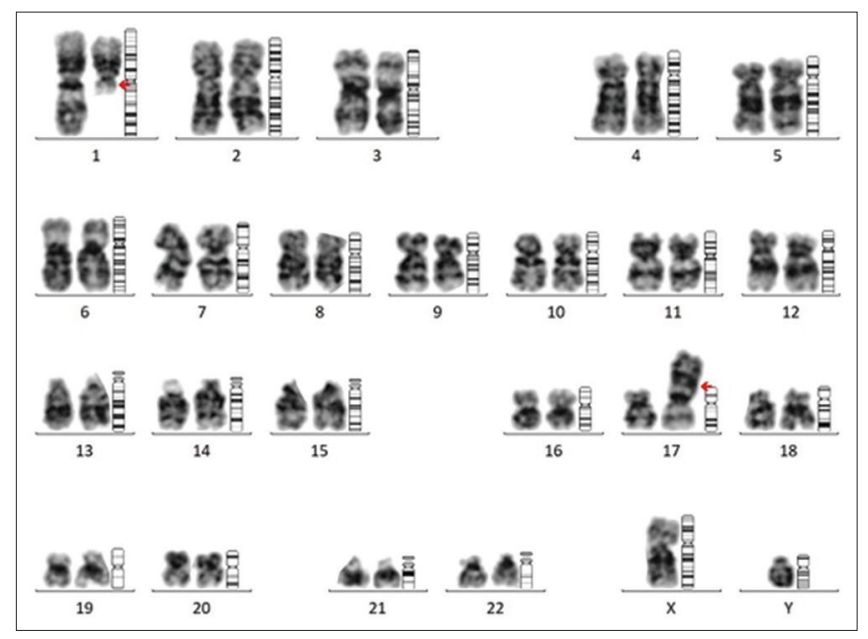

Figure 3: Autosome-autosomal translocation, t(1;17)

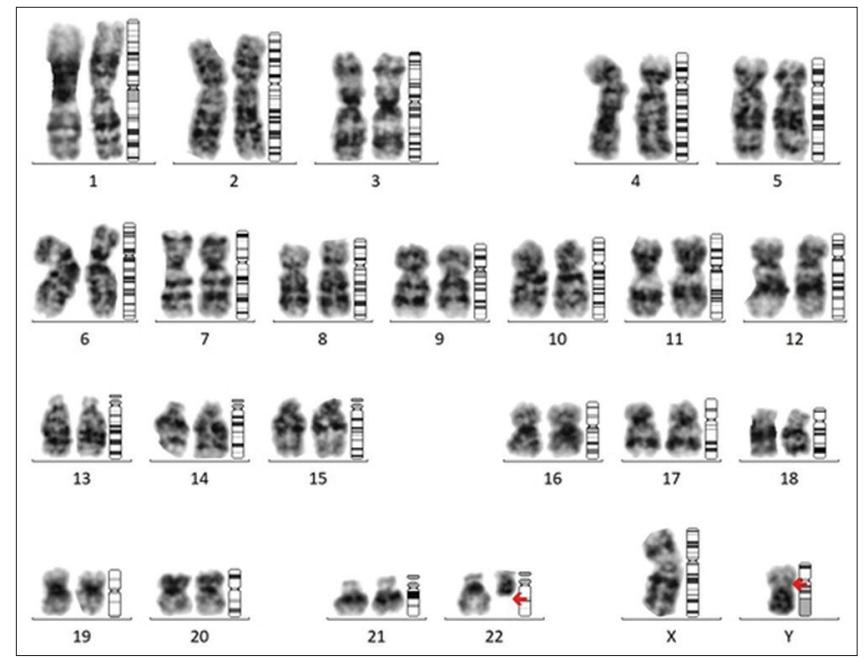

Figure 4: Gonosome-autosomal translocation, $t(y ; 22)$

patients with RPL and men of 3\% infertile [22]. In our study, $1.9 \%$ Rob translocations were detected. One patient with inversion 9 and heteromorphism $(21 \mathrm{ps}+)$ was observed which seemed to be rare in our study (Table 1). The carriers of these translocations were infertile. Most of the Rob translocations are inherited from paternal, nearly $40 \%$ can be de novo translocations due to rearrangements in meiosis [23]. Mostly chromosomal translocations may affect fertility due to disruption of meiosis leading to reduced spermatogenesis as stated above. Some studies indicate that aberrant chromosomal pairing during meiosis in balanced translocation carriers may interfere with certain genetic processes and cause germ cell arrest [5]. Certain cases with MI having Rob translocations cause primary infertility and their semen show oligozoospermia and azoospermia [18].

In addition, geographically, Maharashtra had high incidence of these cases followed by Gujarat and Delhi, indicating environment, hormonal, genetic, and other epigenetic factors which are to be taken into consideration in this report. In-depth epidemiological survey is called for with more sample analysis in future. Few of these infertile cases were with primary and secondary infertility, probably contributed to altered testicular spermatogenesis causing azoospermia, oligospermina, and other semen types to support the reports of earlier workers $[1,19,23]$. These cases may thus serve as clinical reference for genetic counseling and assessment.

\section{CONCLUSIONS}

Auto-autosomal reciprocal translocations are higher in frequency followed by Rob and gonosomal translocations causing MI due to low semen quality and hormone alterations. Few of the cases reported with primary and secondary infertility. Maharashtra exhibited more patients with this genetic cause of MI in our report. Genetic counseling and genetic testing are offered to such families.

\section{ACKNOWLEDGMENT}

We thank to all staffs of our laboratories for their assistance.

\section{AUTHORS' CONTRIBUTIONS}

Ms. Somali and Ms. Krishna along with Dr. Mudra assisted in collection, analysis of karyotyping samples, and writing the paper. Dr. Nidhi and Dr. Parth reviewed the manuscript. Dr. Mudra and Ms. Nirali helped in technical work and preparation of figures. Dr. Sandip and Dr. Rao had edited it critically for publication along with others.

\section{REFERENCES}

1. Dong Y, Du RC, Jiang YT, et al. Impact of chromosomal translocations on male infertility, semen quality, testicular volume and reproductive hormone levels. J Int Med Res 2012;40:2274-83.

2. Shah PS, Shah NP, Shah SC, et al. Y chromosome microdeletion and phenotype correlates with male infertility in Guajarati population. Eastern J Med Sci 2020;5:19-21.

3. Keymolen K, Staessen C, Verpoest W, et al. A proposal for reproductive counseling in carriers of Robertsonian translocations: 10 years of experience with preimplantation genetic diagnosis. Hum Reprod 2009;24:2365-71.

4. Xie X, Guo X, Li F, et al. Genetic and sex hormone analysis of infertile men. J Int Med Res 2020;48:030006051987589.

5. Ching CB, Ko E, Hecht B, et al. Presentation and treatment of subfertile men with balanced translocations: The Cleveland clinic experience. Curr Urol 2012;6:37-42.

6. Balkan M, Tekes S, Gedik A. Cytogenetic and Y chromosome microdeletion screening studies in infertile males with oligozoospermia and azoospermia in Southeast Turkey. J Assist Reprod Genet 2008;25:559-65.

7. Balkan M, Akbas H, Isi H, et al. Cytogenetic analysis of 4216 patients referred for suspected chromosomal abnormalities in Southeast Turkey. Genet Mol Res 2010;9:1094-103.

8. Nidhi S, Parth S, Rutvik R, et al. YqMicrodeletions: Their clinical relevance to Indian and Global population Associated to male infertility: A mini appraisal. Eastern J Med Sci 2021;6:1-8.

9. Vozdova M, Oracova E, Kasikova K, et al. Balanced chromosomal translocations in men: relationships among semen parameters, chromatin integrity, sperm meiotic segregation and aneuploidy. J Assist Reprod Genet 2013;30:391-405.

10. Shah PN, Shah PS, Raval JR, et al. Yq microdeletions and their current status in relation to Indian and Global scenario associated to male infertility: A mini appraisal. Eastern J Med Sci 2021;6:1-8.

11. Rao MV, Shah NP, Raval RJ, et al. Current status of y chromosome microdeletions: Prevalence, distribution, implication and association with male infertility in Indian men a review. J Clin Diagn Res 2021;15:GE1-9. 
12. Vogt PH, Bender U, Zimmer J, et al. Human y chromosome and male infertility: Forward and back from azoospermia factor chromatin structure to azoospermia factor gene function. In: Vogt PH, editor. Monographs in Human Genetics. $21^{\text {st }}$ ed. Basel, Switzerland: Karger AG; 2017. p. 57-73.

13. Suganthi R, Vijesh VV, Vandana N, et al. Y choromosomal microdeletion screening in the workup of male infertility and its current status in India. Int J Fertil Steril 2014;7:253-66.

14. Hotaling J, Carrell DT. Clinical genetic testing for male factor infertility: Current applications and future directions. Andrology 2014;2:339-50.

15. Mafra FA, Christofolini DM, Bianco B, et al. Chromosomal and molecular abnormalities in a group of Brazilian infertile men with severe oligozoospermia or non-obstructive azoospermia attending an infertility service. Int Braz J Urol 2011;37:244-51.

16. Moorhead PS, Nowell PC, Mellman WJ, et al. Chromosome preparations of leukocytes cultured from human peripheral blood. Exp Cell Res 1960;20:613-6.

17. Shaffer LG, McGowan-Jordan J, Schmid M. An International System for Human Cytogenetic Nomenclature. Basal: Karger; 2013.

18. Almesned RK, Alsuhaibani SS, Alali HJ, et al. Male infertility in robertsonian translocation: A case report. Am J Case Rep 2020;21:e921616.

19. Chen $\mathrm{CP}, \mathrm{Wu} \mathrm{PC}, \mathrm{Lin} \mathrm{CJ}$, et al. Unbalanced reciprocal translocations at amniocentesis. Taiwan J Obstet Gynecol 2011;50:48-57.
20. Chang YW, Wang PH, Li WH, et al. Balanced and unbalanced reciprocal translocation: An overview of a 30-year experience in a single tertiary medical center in Taiwan. J Chin Med Assoc 2013;76:153-7.

21. Ghevaria H, Naja R, SenGupta S, et al. Meiotic outcome in two carriers of $\mathrm{Y}$ autosome reciprocal translocations: Selective elimination of certain segregants. Mol Cytogenet 2017;10:1-8.

22. Morin SJ, Eccles J, Iturriaga A, et al. Translocations, inversions and other chromosome rearrangements. Fertil Steril 2017;107:19-26.

23. Arumugam M, Shetty DP, Kadandale JS, et al. Y chromosome microdeletion and cytogenetic findings in male infertility: A cross-sectional descriptive study. Int J Reprod Biomed 2021;19:147-56.

Funding: None; Conflict of Interest: None Stated.

How to cite this article: Shah NP, Mistry K, Kansara M, Sonali K, Thakkar N, Shah PS, et al. A report on chromosomal translocation types in relation to male infertility. Eastern J Med Sci. 2021;6(4):61-65.

DOI: $10.32677 /$ ejms.v6i4.3220 